\title{
An Efficient Computational Approach for Laminar Single Phase Flow of a Fluid (A Single Component or a Homogeneous Mixture)
}

\author{
Seyyed Shahabeddin Azimi*, Mansour Kalbasi \\ Department of Chemical Engineering, Amirkabir University of Technology, Hafez Avenue, Tehran, Iran
}

*Corresponding Author: Seyyed Shahabeddin Azimi, Department of Chemical Engineering, Amirkabir University of Technology, Hafez Avenue, Tehran, Iran

\begin{abstract}
Computer implementation of numerical algorithms for transport phenomena problems (mass, momentum, and heat transfer) that occur in engineering may require too much computer time or storage because of a large number of discretized equations that may have to be solved simultaneously. Considering the finite volume method as a discretization method, we propose an efficient computational approach for laminar single phase flow of a fluid (a single component or a homogeneous mixture) in which the size of discretized equations due to these problems can be greatly reduced, leading to a considerable improvement in simulation execution. As an example, we apply the proposed approach for solving laminar flow of a pure fluid and a nanofluid in a horizontal circular tube and discuss the benefits obtained by this approach in detail. The proposed approach is also independent of Newtonian or non-Newtonian behavior of the fluid.
\end{abstract}

Keywords: Discretized equations; Finite volume method; Flow; Iterative algorithms; Transport phenomena problems

\section{INTRODUCTION}

Transport phenomena problems (mass, momentum, and heat transfer) are described by differential equations, hence, to determine the velocity, temperature, pressure and concentration profiles in various kinds of systems, we need to solve differential equations which cannot be solved analytically in most cases, see for example [1-16].

Therefore, to obtain an approximate solution numerically, we have to use a discretization method which approximates differential equations by a system of algebraic equations (discretized equations) [17] where the finite volume method may be used as a powerful tool. For this purpose the differential equations can be transformed to algebraic equations (nonlinear equations) by the finite volume method in which the discretized equations must be set up at each of the nodal points [18]. To solve this nonlinear system, an iterative algorithm may be applied, i.e., they begin with an initial guess of the optimal values of the variables and generate a sequence of improved estimates until they reach a solution [19]. The general procedure due to the numerical solution of transport phenomena problems is shown schematically in Figure1.

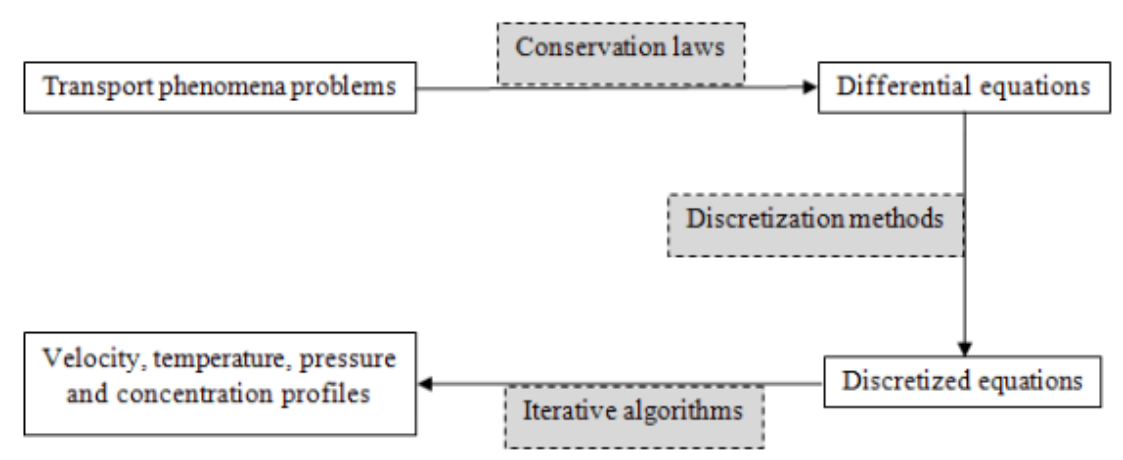

Figure1. A schematic flowchart which shows how a transport phenomena problem is solved numerically.

When the iterative algorithms are programmed on a computer, we may encounter difficulties, including 1) finding good initial guesses for some unknowns, especially in the case where the 
efficiency of the method strongly dependent upon the initial guess 2) evaluation of equations which may be expensive because of a large number of equations and unknowns (too much computer time) 3) requiring too much computer storage on large problems.

In this paper, we propose an efficient computational approach for laminar single phase flow of a fluid (a single component or a homogeneous mixture) in which the size of nonlinear equations (discretized equations) obtained by the finite volume method can be greatly reduced. To clarify benefits of using our proposed approach, as an example, we consider the laminar flow of a pure fluid and a nanofluid in a horizontal circular tube where the improvement in the implementation due to two iterative algorithms is discussed in detail.

This paper is structured as follows. The proposed approach is first presented in section 2. The descretized equations due to a case study are given in section 3 . Two numerical algorithms for solving nonlinear equation are also introduced in section 4 . The proposed approach is applied and discussed in detailed for the case study in section 5. Finally, a summary of main conclusions are given in section 6.

\section{Proposed APPROACH}

The finite volume method uses the integral form of the conservation laws where the solution domain is subdivided into a finite number of small control volumes by a grid which defines the control volume boundaries and computational nodes are located at each control volume [17]. In general, the velocity components, the temperature, the species concentrations (for fluid mixtures) and the pressure have unknown distribution in transport phenomena problems. The scalar variables (temperature, pressure and species concentrations) are defined at the computational nodes (such as $\mathrm{n} 1$ and $\mathrm{n} 2$ in Figure 2) and the velocity components are defined at control volume faces (such as S0 and S2 in Figure 2) [18]. Here, each differential equation (conservation laws at the microscopic level) due to the problem appears as an algebraic equation (conservation laws at the macroscopic level) for each control volume where these algebraic equations (discretized equations) have relations with each other. For instance, to set up a balance of property $\alpha$ in control volumes $n 1$ and $\mathrm{n} 2$ in Figure 2, a flux of $\alpha$ due to fluid flow or diffusion through face $\mathrm{S} 2$ in the positive $\mathrm{x}$ direction is interpreted as an outgoing flux of $\alpha$ for control volume $\mathrm{n} 1$ and an ingoing flux of $\alpha$ for control volume n2. Our proposed approach is based on using these relations.

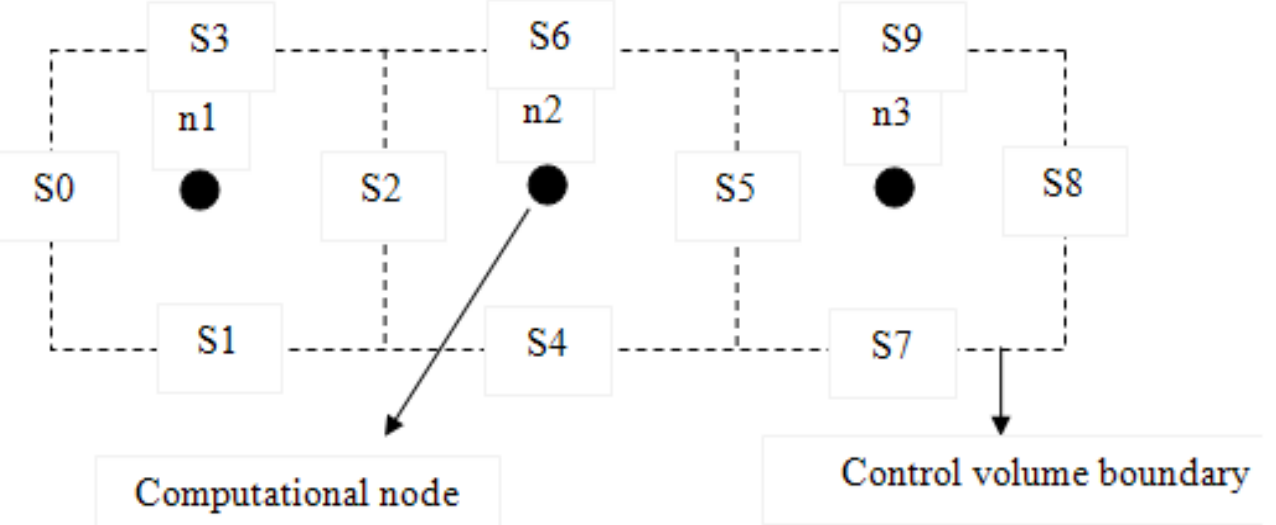

Figure2. A schematic illustration of control volumes including nodes and faces.

\subsection{Analyzing the equation of continuity (for a pure fluid)}

The equation of continuity:

$(\nabla . \rho \mathrm{u})+\frac{\partial \rho}{\partial t}=0$

where $\nabla$ is the differential operator (known as nabla or del), $\rho$ is the density (it can be considered as a function of temperature for a pure fluid), $u$ is the velocity, $t$ is the time and denotes the scalar product of two vectors. Using Gauss' divergence theorem, the discretized form of the equation of continuity can be obtained, for obtaining the discretized form, detailed information were given in books on the 
finite volume method, for example, see Refs [17,18]. The discretized form of the equation of continuity has a form similar to the following equation:

$$
\left(\rho u_{x_{1}} A\right)_{\mathrm{e}}-\left(\rho u_{x_{1}} A\right)_{\mathrm{w}}+\left(\rho u_{x_{2}} A\right)_{\mathrm{n}}-\left(\rho u_{x_{2}} A\right)_{\mathrm{s}}+\left(\rho u_{x_{3}} A\right)_{\mathrm{t}}-\left(\rho u_{x_{3}} A\right)_{\mathrm{b}}+(\text { accumulation term })=0 \text {, }
$$

where $A$ is the cross-sectional area of the control volume face. Each control volume has six faces labeled north (n), south(s), west(w) ,east(e), top(t) and below(b), as will be explained in section 3.2, also, $\left(u_{x 1}, u_{x 2}, u_{x 3}\right)$ are the velocity components in the three coordinate direction $\mathrm{x} 1, \mathrm{x} 2$ and $\mathrm{x} 3$. It can be seen that the coefficients of the velocity components $(\rho A)$ in the discretized form of the equation of continuity are in general independent of the velocity components; this fact suggests that one of the velocity components can be obtained as a function of other unknowns. To better describe the proposed approach, face $\mathrm{w}$ and face e in Eq. (1) are considered as face S0 and face S2 in Figure 2, respectively. Now, if $\left(u_{x 1}\right)_{\mathrm{S} 0}$ at face $\mathrm{S} 0$ due to control volume $\mathrm{n} 1$ is considered to be known, because of the boundary conditions or physical properties of the domain, $\left(u_{x 1}\right)_{\mathrm{S} 2}$ is obtained as

$$
\left(u_{x 1}\right)_{\mathrm{S} 2}=\frac{\left(\rho u_{x 1} A\right)_{\mathrm{S} 0}+\text { other terms }}{(\rho A)_{\mathrm{S} 2}} .
$$

Regarding the discretized form of the continuity equation for control volume $\mathrm{n} 2$ and similar to control volume 1 , we have

$$
\left(u_{x 1}\right)_{\mathrm{S} 5}=\frac{\left(\rho\left(\frac{\left(\rho u_{x 1} A\right)_{\mathrm{S} 0}+\text { other terms }}{(\rho A)_{\mathrm{S} 2}}\right) A\right)_{\mathrm{S} 2}+\text { other terms }}{(\rho A)_{\mathrm{S} 5}} .
$$

Hence, using this approach, all $u_{x_{1}}$ along the $\mathrm{x} 1$ direction can be obtained, one after another, as functions of $u_{x_{2}}, u_{x_{3}}$ and $\rho$, shown schematically in Figure 3.

Therefore, it can be concluded that the discretized form of the continuity equation has a special structure (i.e., the coefficients of the velocity components are in general independent of the velocity components) which can be used to give one velocity component as a function of density (temperature) and two other velocity components. It should be noted that when a discretized equation is used to obtain an unknown as a function of other unknowns, that equation is removed from the nonlinear equations due to the problem.

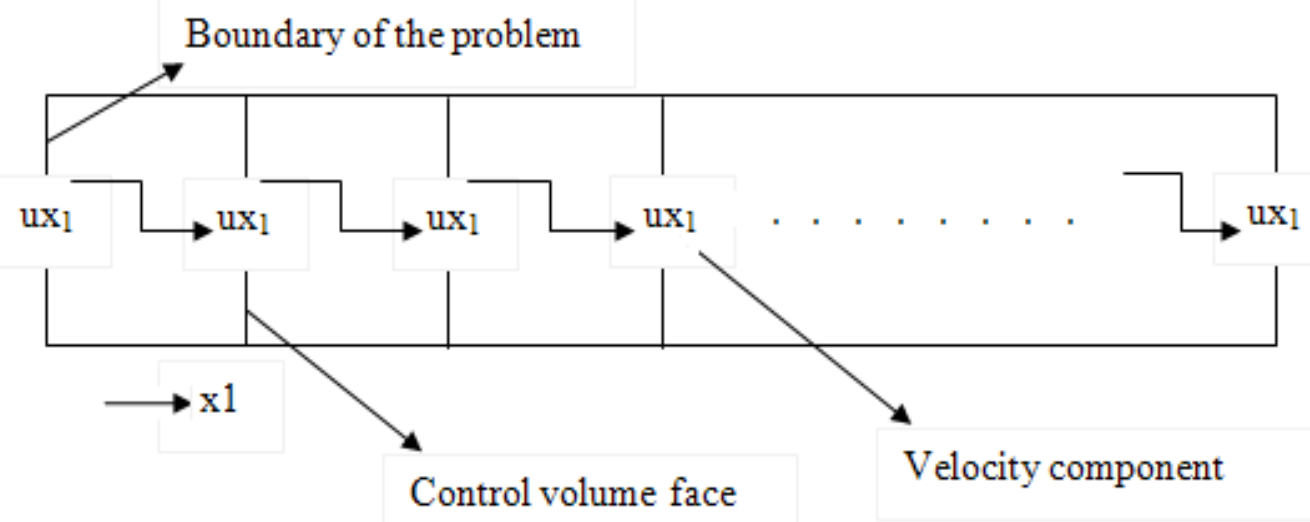

Figure3. A part of grid used in section 2.1.

\subsection{Analyzing the Equation of Continuity and the Equation of Continuity Due to Species a (For A Nanofluid)}

The equation of continuity for nanoparticles in a nanofluid (or for species A in a binary fluid) which behaves as a single phase fluid:

$\nabla \cdot\left(\phi \rho_{p} \overrightarrow{\mathrm{u}}\right)+$ Diffusionterms+Reactionterm+accumulationterm $=0$, 
where $\rho_{p}$ is the density of the nanoparticle, $\phi$ is the nanoparticle volume fraction. It should be noted that the single phase model can be selected for modeling of the solid-liquid mixtures which the solid particles move in stokes' regime (homogeneous mixtures) [20].

The discretized form of the above equation has a form similar to the following equation:

$\left(\phi \rho_{p} u_{x 1} A\right)_{\mathrm{e}}-\left(\phi \rho_{p} u_{x 1} A\right)_{\mathrm{w}}+\left(\phi \rho_{p} u_{x_{2}} A\right)_{\mathrm{n}}-\left(\phi \rho_{p} u_{x_{2}} A\right)_{\mathrm{s}}+\left(\phi \rho_{p} u_{x 3} A\right)_{\mathrm{t}}-\left(\phi \rho_{p} u_{x_{3}} A\right)_{\mathrm{b}}+($ other terms $)=0$. (3)

Similar to the previous section, the coefficients of the velocity components $\left(\phi \rho_{p} A\right)$ in the discretized form of the equation of continuity due to the nanoparticle are independent of the velocity components. Here, we consider two discretized equations, Eqs. (1) and (3) for each control volume. We begin with the control volume which its two faces lie on the boundaries of the problem, see node $\mathrm{m}$ in Figure 4. Considering Eqs. (1) and (3) in this control volume ( $\mathrm{w}=\mathrm{f} 0, \mathrm{e}=\mathrm{f} 2, \mathrm{~s}=\mathrm{f} 1$ and $\mathrm{n}=\mathrm{f} 3$ ), it is assumed that $\left(u_{x_{1}}\right)_{\mathrm{f} 0}$ and $\left(u_{x_{2}}\right)_{\mathrm{f} 1}$ be known because of the boundary conditions of the problem. Therefore, $\left(u_{x_{1}}\right)_{\mathrm{f} 2}$ and $\left(u_{x_{2}}\right)_{\mathrm{f} 3}$ can be obtained as a function of other unknowns by using Eqs. (1) and (3) as follows:

$$
\begin{aligned}
& \text { Eq.(1) } \rightarrow\left(\rho u_{x 1} A\right)_{\mathrm{f} 2}-(\rho \underbrace{u_{x 1}}_{\text {known }} A)_{\mathrm{f} 0}+\left(\rho u_{x_{2}} A\right)_{\mathrm{f} 3}-(\rho \underbrace{u_{x_{2}}}_{\text {known }} A)_{\mathrm{f} 1}+\text { other terms }=0, \\
& \text { Eq.(3) } \rightarrow\left(\phi \rho_{p} u_{x 1} A\right)_{\mathrm{f} 2}-(\phi \rho_{p} \underbrace{u_{x 1}}_{\text {known }} A)_{\mathrm{f} 0}+\left(\phi \rho_{p} u_{x 2} A\right)_{\mathrm{f} 3}-(\phi \rho_{p} \underbrace{u_{x 2} A}_{\text {known }})_{\mathrm{f} 1}+\text { other terms }=0 .
\end{aligned}
$$

Similarly, we can obtain all $\left(u_{x_{1}}\right)$ and $\left(u_{x_{2}}\right)$, one after another, in the positive $\mathrm{x} 2$ direction toward the last control volume (the gray control volume in Figure 4). This procedure can also be applied for the next control volumes in the positive $\mathrm{x} 1$ direction which leads to obtaining two velocity components as a function of other unknowns.

It should be noted that for a mixture of $\mathrm{N}$ species, only ( $\mathrm{N}-1)$ continuity equations can be considered. Therefore, for a ternary fluid, all three velocity components can be obtained as functions of other unknowns, similar to the procedure explained for a binary fluid.

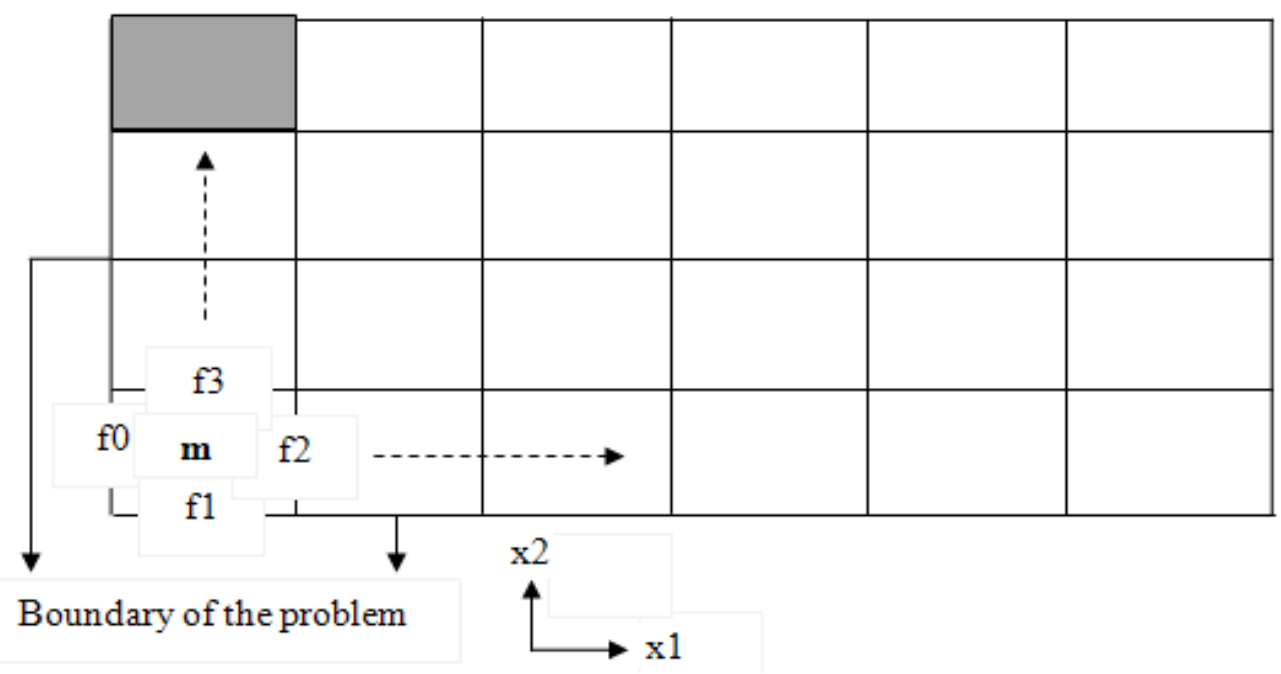

Figure4. The two-dimensional grid used in section 2.2.

\subsection{Analyzing the equation of motion (for a pure fluid or a nanofluid)}

The equation of motion:

$\nabla \cdot(\rho \overrightarrow{\mathrm{u}} \overrightarrow{\mathrm{u}})=-\nabla p-[\nabla \cdot \tau]+\rho \overrightarrow{\mathrm{g}}$, where $p$ is the pressure, $\tau$ is the shear stress tensor, and $\mathrm{g}$ is the gravity vector. Considering the above equation, it can be seen that the pressure appears only as $\nabla p$. The above 
equation as a vector equation with components in each of the three coordinate directions $\mathrm{x} 1, \mathrm{x} 2$ and $\mathrm{x} 3$, gives three discretized equations in the three coordinate directions in which $\nabla p$ appears as $\left(\left(\frac{\partial p}{\partial \times 1}\right) \times V o l\right),\left(\left(\frac{\partial p}{\partial \times 2}\right) \times V o l\right)$ or $\left(\left(\frac{\partial p}{\partial \times 3}\right) \times V o l\right)$ where $V o l$ is the volume of the control volume. Considering the boundary condition due to the pressure in one of the three coordinate directions (e.g., $\mathrm{x} 1$ ), $\mathrm{P}_{\mathrm{i}}$ in Figure 5, we have

Discretized form for node $n 1 \rightarrow\left(\frac{\mathrm{p}(\mathrm{n} 1)-\overbrace{\mathrm{p}_{\mathrm{i}}}^{\text {known }}}{\mathrm{d} 0}\right) \times V o l+$ other terms $=0$,

Discretized form for node $\mathrm{n} 2 \rightarrow\left(\frac{\mathrm{p}(\mathrm{n} 2)-\mathrm{p}(\mathrm{n} 1)}{\mathrm{d} 1}\right) \times V o l+$ other terms $=0$.

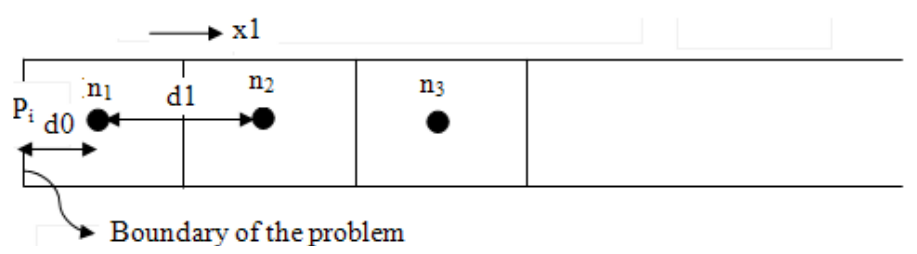

Figure5. A part of grid used in section 2.3.

Considering Eq. (4.a), $\mathrm{P}(\mathrm{n} 1)$ can be obtained as a function of other unknowns, then, using $\mathrm{P}(\mathrm{n} 1)$ in Eq. (4.b), $\mathrm{P}(\mathrm{n} 2)$ can also be obtained as a function of other unknowns, and so on. Therefore, we can obtain all the pressures at the nodes of control volumes, one after another, in the positive x1direction.

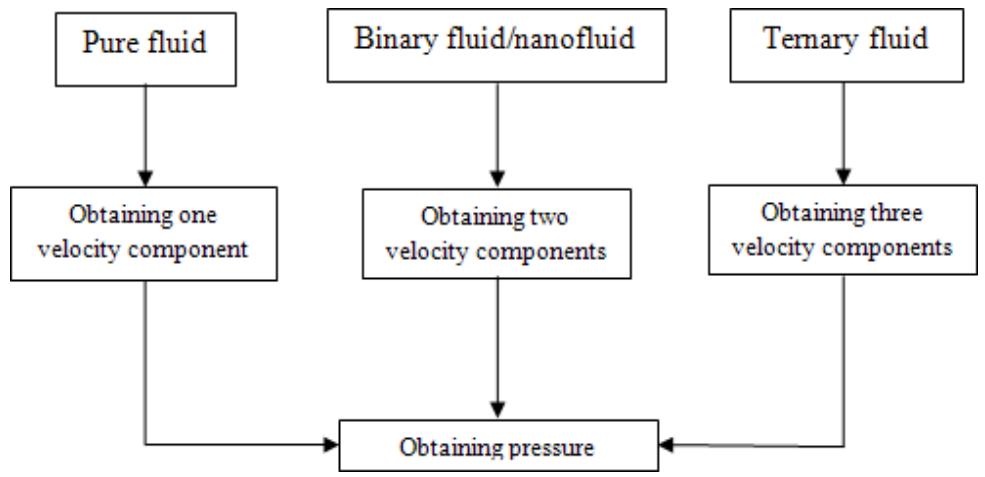

Figure6. A schematic flowchart which shows an overall view of the proposed approach.

\section{Steady laminar Flow of a Nanofluid (Binary Fluid) and a Pure Fluid in a Horizontal Circular Tube (A CaSe Study)}

The flow of fluids in circular tubes is encountered frequently in physics, chemistry, biology, and engineering [21], so one of the most widely used flow geometries in literature is the three- dimensional flow of a fluid through a circular tube. When we speak of "three-dimensional flow", we mean that all the flow parameters (e.g., velocity) are functions of three space coordinates, adopting the cylindrical coordinates, which are the natural coordinates for describing positions in a pipe of circular cross section [21], we consider here the radial, angular and axial directions $(r, \theta, z)$.

Here, we consider a nanofluid/pure fluid in the three-dimensional developing laminar flow in a circular tube, as the result of a pressure difference, this flow geometry may be considered in both heat and mass transfer problems. Nanofluids can be considered as single phase fluids with changed thermo physical properties [22]. The conservation equations are given in vector notation.

\subsection{Differential Equations}

The equation of continuity:

$$
\text { nanofluid } \rightarrow\left(\nabla . \rho_{n f} \mathbf{u}\right)=0, \quad \text { pure fluid } \rightarrow(\nabla . \rho \mathbf{u})=0,
$$


where $\rho_{n f}$ is the density of the nanofluid.

The equation of continuity for the nanoparticle:

$\nabla \cdot\left(\phi \rho_{p} \mathrm{u}\right)+\nabla \cdot(\mathrm{I})=0$

where I is the vector of the mass rate due to the nanoparticle diffusion.

The equation of motion:

$$
\text { nanofluid } \rightarrow \nabla \cdot\left(\rho_{n f} \mathrm{uu}\right)=-\nabla p-[\nabla . \tau]+\rho_{n f} \mathrm{~g}, \text { pure fluid } \rightarrow \nabla .(\rho \mathrm{uu})=-\nabla p-[\nabla . \tau]+\rho \mathrm{g},
$$

The equation of energy:

$$
\text { nanofluid } \rightarrow \nabla \cdot\left(\mathrm{u}\left(\rho c_{p}\right)_{n f} T\right)+\nabla \cdot\left(-k_{n f} \nabla T\right)=0 \text {, pure fluid } \rightarrow \nabla \cdot\left(\mathrm{u}\left(\rho c_{p}\right) T\right)+\nabla \cdot(-k \nabla T)=0,
$$

where $T$ is the temperature, $\left(c_{p}\right)_{n f}$ is the specific heat of the nanofluid, $\left(c_{p}\right)$ is the specific heat of the pure fluid, $k_{n f}$ is the thermal conductivity of the nanofluid and $k$ is the thermal conductivity of the pure fluid. There is no need to give the boundary conditions since the proposed approach has no dependency on boundary conditions. Equation of motion, Eq. (7), gives three partial differential equations, therefore, in general we have six partial differential equations for the nanofluid (binary fluid) and five partial differential equations for the pure fluid. In general, unknowns are $T, p, u_{r}, u_{\theta}, u_{z}$ and $\phi$ (for the nanofluid). For instance, to obtain the temperature profile for heat transfer problems, theses differential equations must be solved simultaneously.

\subsection{Discretized Equations}

The domain (tube) is divided into discrete control volumes in which the nodal points are placed. Figure 7 shows the shape of a control volume in the domain which has six faces labeled north(n), south(s), west(w), east(e), top(t) and below(b). Considering unit vectors $\delta_{\mathrm{r}}, \delta_{\theta}, \delta_{\mathrm{z}}$ in three directions, face $\mathrm{w}$ is the face with the outwardly directed normal vector in $\delta_{\mathrm{z}}$ direction. For faces $(\mathrm{e}, \mathrm{n}, \mathrm{s}, \mathrm{t}, \mathrm{b})$, the outward normal vectors are in $\left(-\delta_{\mathrm{z}}\right), \delta_{\mathrm{r}},\left(-\delta_{\mathrm{r}}\right), \delta_{\theta}$ and $\left(-\delta_{\theta}\right)$ directions, respectively. Applying the Gauss' divergence theorem, the discretized equations can be obtained, here, we neglect to give details of obtaining the discretized equations.

$$
\left(\rho_{n f} u_{z} A\right)_{\mathrm{e}}-\left(\rho_{n f} u_{z} A\right)_{\mathrm{W}}+\left(\rho_{n f} u_{r} A\right)_{\mathrm{n}}-\left(\rho_{n f} u_{r} A\right)_{\mathrm{s}}+\left(\rho_{n f} u_{\theta} A\right)_{\mathrm{t}}-\left(\rho_{n f} u_{\theta} A\right)_{\mathrm{b}}=0
$$

where $\rho_{n f}$ is replace by $\rho$ in the discretized form of Eq. (5) for the pure fluid.

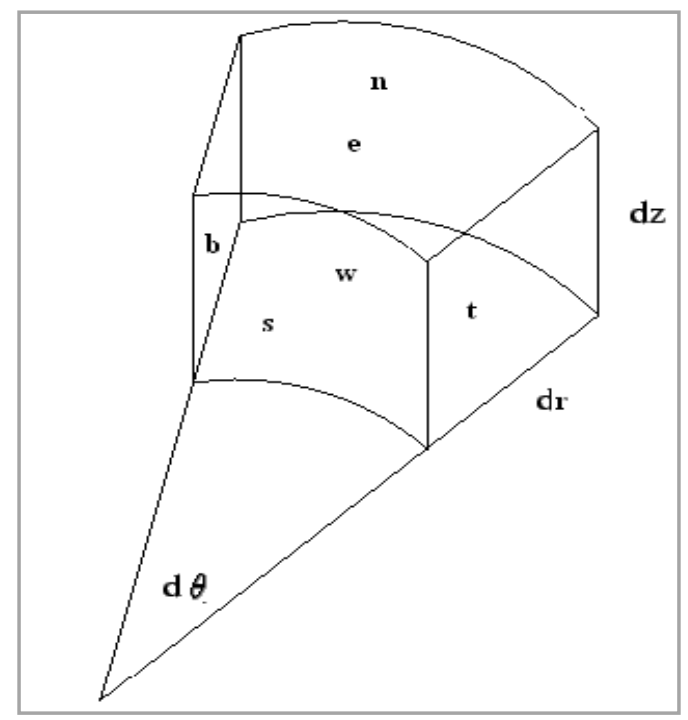

Figure7. Illustration of a control volume in cylindrical coordinates. 
The discretized form of Eq.(6):

$$
\begin{aligned}
& \left(\phi \rho_{p} u_{z} A\right)_{\mathrm{e}}-\left(\phi \rho_{p} u_{z} A\right)_{\mathrm{W}}+\left(\phi \rho_{p} u_{r} A\right)_{\mathrm{n}}-\left(\phi \rho_{p} u_{r} A\right)_{\mathrm{s}}+\left(\phi \rho_{p} u_{\theta} A\right)_{\mathrm{t}}-\left(\phi \rho_{p} u_{\theta} A\right)_{\mathrm{b}} \\
& \left(I_{z} A\right)_{\mathrm{e}}-\left(I_{z} A\right)_{\mathrm{W}}+\left(I_{r} A\right)_{\mathrm{n}}-\left(I_{r} A\right)_{\mathrm{s}}+\left(I_{\theta} A\right)_{\mathrm{t}}-\left(I_{\theta} A\right)_{\mathrm{b}}=0 .
\end{aligned}
$$

The discretized form of Eq. (7) for the nanofluid, in the radial direction:

$$
\begin{aligned}
& \left(\rho_{n f} u_{z} u_{r} A\right)_{\mathrm{e}}-\left(\rho_{n f} u_{z} u_{r} A\right)_{\mathrm{W}}+\left(\rho_{n f} u_{r} u_{r} A\right)_{\mathrm{n}}-\left(\rho_{n f} u_{r} u_{r} A\right)_{\mathrm{S}}+ \\
& +\left(\rho_{n f} u_{\theta} u_{r} A\right)_{\mathrm{t}}-\left(\rho_{n f} u_{\theta} u_{r} A\right)_{\mathrm{b}}+\frac{p_{\text {node }}-p_{\mathrm{S}}}{d r} V+ \\
& \left(\left(\tau_{z r} A\right)_{\mathrm{e}}-\left(\tau_{z r} A\right)_{\mathrm{W}}+\left(\tau_{r r} A\right)_{\mathrm{n}}-\left(\tau_{r r} A\right)_{\mathrm{S}}\right)+\left(\tau_{\theta r} A\right)_{\mathrm{t}}-\left(\tau_{\theta r} A\right)_{\mathrm{b}}-\left(\bar{\rho}_{n f}(-g)\right) V=0,
\end{aligned}
$$

where $V$ is the volume of the control volume, $d r$ is the node spacing in the radial direction, $p_{\text {node }}$ is the pressure at the considered node and $p_{\mathrm{S}}$ is the pressure at its neighboring node in the radial direction, see Figure 8 , and $\bar{\rho}_{n f}$ is the average of $\rho_{n f}$ which can be evaluated at the control volume node. Also, $\rho_{n f}$ is replaced by $\rho$ in the above equation for the pure fluid.

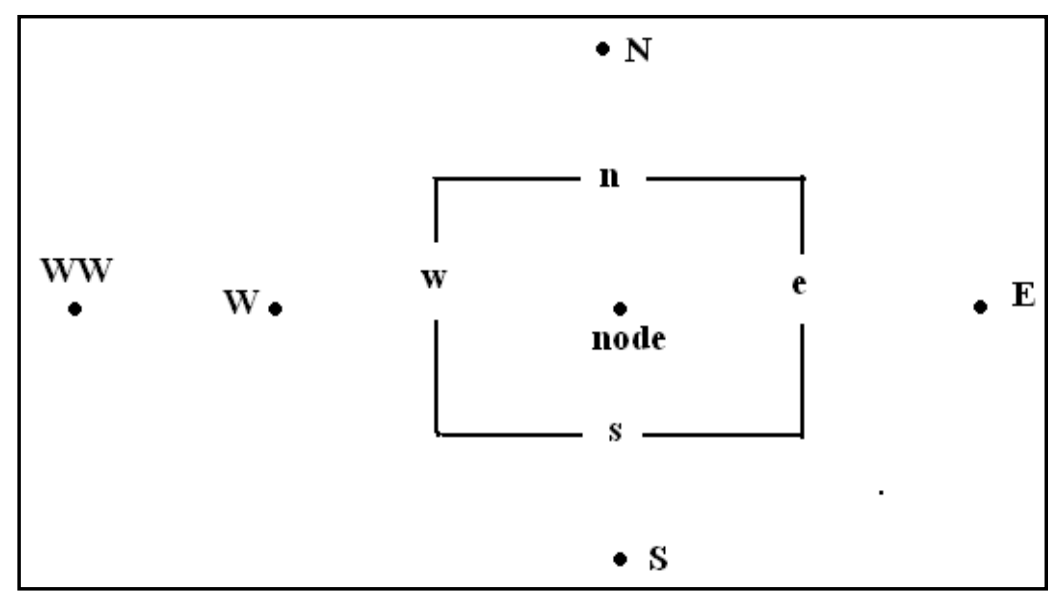

Figure8. Two-dimensional illustration of a control volume with its surrounding nodes.

The discretized form of Eq. (7) for the nanofluid, in the angular direction:

$$
\begin{aligned}
& \left(\rho_{n f} u_{z} u_{\theta} A\right)_{\mathrm{e}}-\left(\rho_{n f} u_{z} u_{\theta} A\right)_{\mathrm{W}}+\left(\rho_{n f} u_{r} u_{\theta} A\right)_{\mathrm{n}}-\left(\rho_{n f} u_{r} u_{\theta} A\right)_{\mathrm{s}}+ \\
& +\left(\rho_{n f} u_{\theta} u_{\theta}^{A}\right)_{\mathrm{t}}-\left(\rho_{n f} u_{\theta} u_{\theta} A\right)_{\mathrm{b}}+\frac{p_{\text {node }}-p_{\mathrm{B}}}{d \theta} V \\
& +\left(\left(\tau_{z} \theta^{A}\right)_{\mathrm{e}}-\left(\tau_{z} \theta^{A}\right)_{\mathrm{W}}+\left(\tau_{r} \theta^{A}\right)_{\mathrm{n}}-\left(\tau_{r} \theta^{A}\right)_{\mathrm{s}}+\left(\tau_{\theta \theta^{A}}\right)_{\mathrm{t}}-\left(\tau_{\theta \theta} A\right)_{\mathrm{b}}\right)=0,
\end{aligned}
$$

where $d \theta$ is the node spacing in the angular direction and $p_{\mathrm{B}}$ is the pressure at its neighboring node in the angular direction. Also, $\rho_{n f}$ is replaced by $\rho$ in the above equation for the pure fluid.

The discretized form of Eq. (7) for the nanofluid, in the axial direction:

$$
\begin{aligned}
& \left(\rho_{n f} u_{z} u_{z} A\right)_{\mathrm{e}}-\left(\rho_{n f} u_{z} u_{z} A\right)_{\mathrm{W}}+\left(\rho_{n f} u_{z} u_{r} A\right)_{\mathrm{n}}-\left(\rho_{n f} u_{z} u_{r} A\right)_{\mathrm{s}}+ \\
& +\left(\rho_{n f} u_{\theta} u_{z} A\right)_{\mathrm{t}}-\left(\rho_{n f} u_{\theta} u_{z} A\right)_{\mathrm{b}}+\frac{p_{\text {node }}-p_{\mathrm{W}}}{d z} V \\
& +\left(\left(\tau_{z z} A\right)_{\mathrm{e}}-\left(\tau_{z z} A\right)_{\mathrm{W}}+\left(\tau_{r z} A\right)_{\mathrm{n}}-\left(\tau_{r z} A\right)_{\mathrm{s}}+\left(\tau_{\theta z} A\right)_{\mathrm{t}}-\left(\tau_{\theta z} A\right)_{\mathrm{b}}\right)=0,
\end{aligned}
$$


where $d z$ is the node spacing in the axial direction and $p_{\mathrm{W}}$ is the pressure at its neighboring node in the axial direction. Also, $\rho_{n f}$ is replaced by $\rho$ in the above equation for the pure fluid.

The discretised form of Eq. (8) for the nanofluid:

$$
\begin{aligned}
& \left(u_{z}\left(\rho c_{p}\right)_{n f} T A\right)_{\mathrm{e}}-\left(u_{z}\left(\rho c_{p}\right)_{n f} T A\right)_{\mathrm{W}}+\left(u_{r}\left(\rho c_{p}\right)_{n f} T A\right)_{\mathrm{n}}-\left(u_{r}\left(\rho c_{p}\right)_{n f} T A\right)_{\mathrm{S}}+ \\
& \left(u_{\theta}\left(\rho c_{p}\right)_{n f} T A\right)_{\mathrm{t}}-\left(u_{\theta}\left(\rho c_{p}\right)_{n f} T A\right)_{\mathrm{b}}-\left(k_{n f} \frac{\partial T}{\partial z} A\right)_{\mathrm{e}}+\left(k_{n f} \frac{\partial T}{\partial z} A\right)_{\mathrm{W}}- \\
& \left(k_{n f} \frac{\partial T}{\partial r} A\right)_{\mathrm{n}}+\left(k_{n f} \frac{\partial T}{\partial r} A\right)_{\mathrm{s}}-\left(k_{n f} \frac{1}{r} \frac{\partial T}{\partial \theta} A\right)_{\mathrm{t}}+\left(k_{n f} \frac{1}{r} \frac{\partial T}{\partial \theta} A\right)_{\mathrm{b}}=0 .
\end{aligned}
$$

Also, $k_{n f}$ and $\left(\rho c_{p}\right)_{n f}$ are replaced by $k$ and $\left(\rho c_{p}\right)$, respectively, in the above equation for the pure fluid.

The discretized equations due to each control volume, construct a system of nonlinear equations which its size depend on the number of control volumes in the domain as

$$
\begin{aligned}
& \text { Number of partitions in the } r \text {-direction }=r \text {-part } \\
& \text { Number of partitions in the } \theta \text { - direction }=\theta \text {-part } \\
& \text { Number of partitions in the } \mathrm{z} \text { - direction }=\mathrm{z} \text {-part } \\
& \text { Number of control volumes in the domain }=(\text { r-part }) \times(\theta \text {-part }) \times(z \text {-part })=n
\end{aligned}
$$

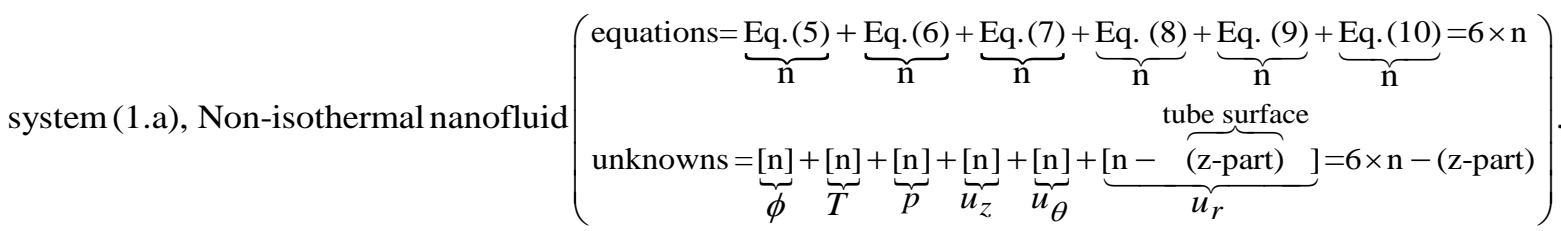

System (1.a), as a very general case, is due to the flow of a nanofluid with varying temperature, while we can consider other conditions which lead to simpler systems. Considering the flow of a nanofluid with constant temperature (the temperature $T$ and the energy equation, Eq. (14), are removed from the nonlinear system), we have

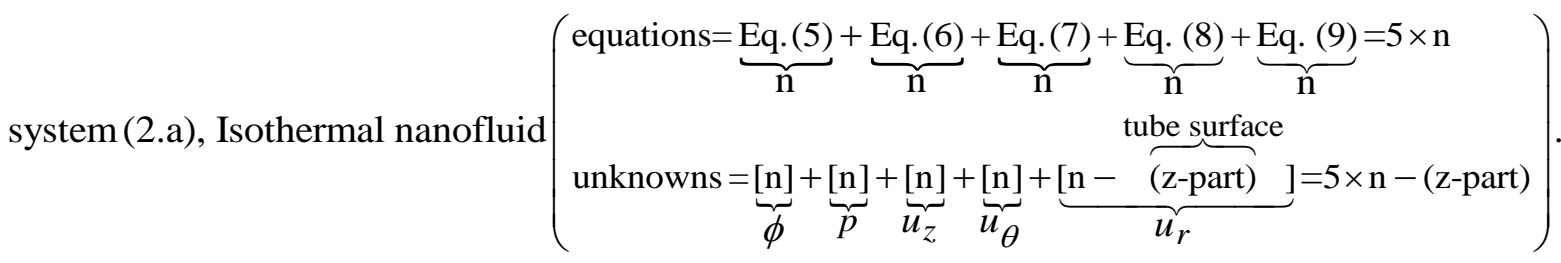

Considering the pure fluids, we have

$\operatorname{system(3.a),~Non-isothermal~pure~fluid~}$

$$
\left(\begin{array}{l}
\text { equations }=\underbrace{\mathrm{Eq} \cdot(5)}_{\mathrm{n}}+\underbrace{\mathrm{Eq} \cdot(7)}_{\mathrm{n}}+\underbrace{\mathrm{Eq} \cdot(8)}_{\mathrm{n}}+\underbrace{\mathrm{Eq} \cdot(9)}_{\mathrm{n}}+\underbrace{\mathrm{Eq} \cdot(10)}_{\mathrm{n}}=5 \times \mathrm{n} \\
\text { unknowns }=\underbrace{[\mathrm{n}]}_{T}+\underbrace{[\mathrm{n}]}_{p}+\underbrace{[\mathrm{n}]}_{u_{z}}+\underbrace{[\mathrm{n}]}_{u_{\theta}}+\underbrace{[\mathrm{n}-\overbrace{\text { (z-part) surface }}^{\mathrm{n}-\text { part }}]}_{u_{r}}]=5 \times \mathrm{n}-(\mathrm{z}-\text { part })
\end{array}\right),
$$

$\operatorname{system}$ (4.a), Isothermal pure fluid $\left(\begin{array}{l}\text { equations }=\underbrace{\text { Eq. (5) }}_{\mathrm{n}}+\underbrace{\text { Eq. }(7)}_{\mathrm{n}}+\underbrace{\text { Eq. (8) }}_{\mathrm{n}}+\underbrace{\text { Eq. }(9)}_{\mathrm{n}}=4 \times \mathrm{n} \\ \text { unknowns }=\underbrace{[\mathrm{n}]}_{p}+\underbrace{[\mathrm{n}]}_{\left.u_{z}\right]}+\underbrace{[\mathrm{n}]}_{u_{\theta}}+\underbrace{[\mathrm{n}-\overbrace{\text { (z-part) }}^{\mathrm{zurface}}}_{u_{r}}]=4 \times \mathrm{n} \text {-(z-part) }\end{array}\right)$. 
Indeed, nonlinear systems (2.a), (3.a) and (4.a) are simplified version of system (1.a), which may be encountered in transport phenomena problems. When the equations outnumber the unknowns, combining the extra equations with the other remaining equations, yields a system with the same number of unknowns and equations.

\section{NUMERiCAl Algorithms}

To solve nonlinear equations, optimization algorithms can be used in which a merit function $\mathrm{f}$ is defined as follows [19]:

$\mathrm{f}(\mathrm{X})=\frac{1}{2}\|\mathrm{~F}(\mathrm{X})\|^{2}=\frac{1}{2} \sum \mathrm{F}_{\mathrm{i}}^{2}$,

where $\mathrm{F}$ is the residual vector and $\mathrm{X}$ is the vector of unknowns. The steepest descent method (SDM), as an iterative algorithm, may be used for the search direction $S$ :

$$
\mathrm{S}=-\nabla \mathrm{f}=-\left[\begin{array}{c}
\frac{\partial \mathrm{f}}{\partial \mathrm{x}_{1}} \\
\vdots \\
\frac{\partial \mathrm{f}}{\partial \mathrm{x}_{\mathrm{n}}}
\end{array}\right] \quad, \quad \mathrm{X}=\left[\begin{array}{c}
\mathrm{x}_{1} \\
\vdots \\
\mathrm{x}_{\mathrm{n}}
\end{array}\right] \text {. }
$$

Since derivatives due to $\nabla \mathrm{f}$ are not practically available, $\nabla \mathrm{f}$ is approximated by the finite difference:

$$
\frac{\partial \mathrm{f}}{\partial \mathrm{x}}=\frac{f(x+\varepsilon)-f(X)}{\varepsilon} .
$$

Indeed, for estimation each component of $\nabla f$, all components of $F$ should be evaluated. Therefore, at each iteration of the SDM, the computer program must evaluate $(\text { num })^{2}$ discretized equations where num is the number of either equations or unknowns. However, the SDM can be excruciatingly slow on difficult problems [19]. A powerful search direction, as the quasi-Newton search direction, is the Levenberg-Marquardt method (LMM):

$$
\begin{aligned}
& \left(\mathbf{J}^{\mathbf{T}} \mathbf{J}+\lambda \mathbf{I}\right) \mathrm{S}=-\mathbf{J}^{\mathbf{T}} \mathbf{F}, \\
& \mathbf{J}=\left[\begin{array}{ccc}
\frac{\partial \mathbf{F}_{1}}{\partial \mathbf{x}_{1}} & \cdots & \frac{\partial \mathbf{F}_{1}}{\partial \mathbf{x}_{\mathbf{n}}} \\
\vdots & & \vdots \\
\frac{\partial \mathbf{F}_{\mathbf{n}}}{\partial \mathbf{x}_{1}} & \cdots & \frac{\partial \mathbf{F}_{\mathbf{n}}}{\partial \mathbf{x}_{\mathbf{n}}}
\end{array}\right],
\end{aligned}
$$

where $\mathrm{J}$ is the Jacobian of $\mathrm{F}, \mathrm{J}^{\mathrm{T}}$ is the transpose of $\mathrm{J}, \lambda$ is a positive damping factor and $\mathrm{I}$ is the identity matrix. Computation of $S$ in the LMM includes three steps: 1) estimation of the Jacobian matrix 2) calculation of the matrix $\mathbf{J}^{\mathrm{T}} \mathbf{J}$ 3) solving a linear system. The Jacobian is estimated column by column, which may be expensive where all equations are evaluated for each unknown since it is practically very difficult to separate related equations during evaluation of an unknown. In order to estimate the Jacobian for the nonlinear system at each iteration, the computer program must evaluate $(\text { num })^{2}$ discretized equations. Also, the Jacobian occupies (num $)^{2}$ units of memory (it can be assumed as 2 Bytes for each real number). Each element of the matrix $\mathrm{J}^{\mathrm{T}} \mathrm{J}$ is obtained by multiplying of two columns of the Jacobian. Since this matrix is symmetric, it is sufficient to calculate $(\mathrm{m}(\mathrm{m}+1)) / 2$ elements for matrix $\mathrm{m} \times \mathrm{m}$, therefore, $\left(\mathrm{m}^{2}(\mathrm{~m}+1)\right) / 2$ multiplications and $\left(\mathrm{m}^{2}(\mathrm{~m}+1)\right) / 2$ additions are required. In order to calculate $\mathbf{J}^{\mathrm{T}} \mathbf{J}$ for the nonlinear system, 
$\left((\text { num })^{2} \times((\right.$ num $\left.)+1)\right) / 2$ multiplications and $\left((\text { num })^{2} \times((\right.$ num $\left.)+1)\right) / 2$ additions are required and $\mathrm{J}^{\mathrm{T}} \mathbf{J}$ occupies (num) ${ }^{2}$ units of memory. A common method for solving a linear system is the Gaussian elimination method where the pivot elements must be non-zero. For stability, complete pivoting may be used to ensure correct solution in which all entries in the whole sub matrix are considered (interchanging rows and columns to achieve the highest accuracy). In order to solve the linear system in the nonlinear system, $($ num -1$)$ complete pivot operations (searching in sub matrix and interchanging rows and columns) and (num -1$)$ row operations are required.

\section{Applying the Proposed Approach For The CASE Study}

\subsection{The Pure fluid}

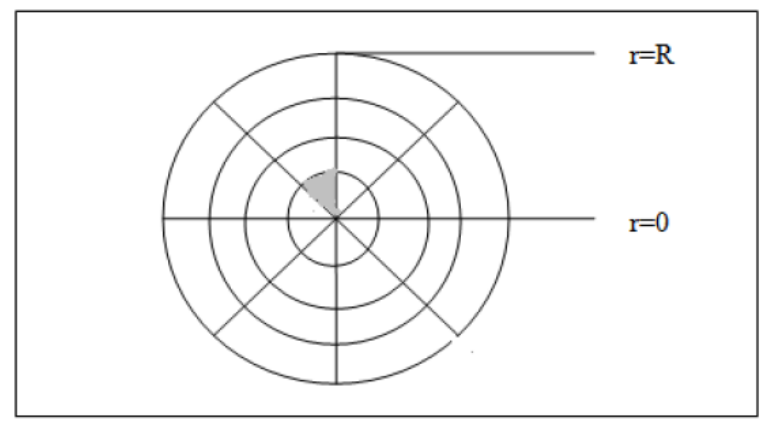

Figure9. Two-dimensional illustration of the tube cross section due to control volumes.

\begin{tabular}{|c|}
\hline $\mathrm{S}_{\mathrm{n}}$ \\
\hline$S_{n-1}$ \\
\hline $\mathrm{S}_{3}$ \\
\hline $\mathrm{S}_{2}$ \\
\hline $\mathrm{S}_{1}$ \\
\hline
\end{tabular}

Figure10. An illustration of the partitions made by the finite volume method in the tube.

The control volumes which their south faces lie in $\mathrm{r}=0$, e.g. the gray region in Figure 9 or $\mathrm{S}_{1}$ in Figure 10 , may now be considered where $(A)_{\mathrm{S}}=0$ (because of the physical property of circular tubes) and therefore Eq. (9) can be simplified as

$$
\left(\rho u_{z} A\right)_{\mathrm{e}}-\left(\rho u_{z} A\right)_{\mathrm{W}}+\left(\rho u_{r} A\right)_{\mathrm{n}}+\left(\rho u_{\theta} A\right)_{\mathrm{t}}-\left(\rho u_{\theta} A\right)_{\mathrm{b}}=\mathrm{O} \text {, }
$$

where $\rho$ can be assumed as a function of temperature, therefore, $\left(u_{r}\right)_{\mathrm{n}}$ is then obtained as a function of $T, u_{\theta}$ and $u_{z}$ :

$$
\left(u_{r}\right)_{\mathbf{n}}=\frac{\left(\rho u_{z} A\right)_{\mathrm{w}}-\left(\rho u_{z} A\right)_{\mathrm{e}}+\left(\rho u_{\theta} A\right)_{\mathrm{t}}-\left(\rho u_{\theta^{A}}\right)_{\mathrm{b}}}{(\rho A)_{\mathbf{n}}} .
$$

Hence, all radial velocities $\left(u_{r}\right)$ in this region, $S_{1}$ in Figure 10, are obtained as a function of $T, u_{\theta}$ and $u_{z}$. To obtain $u_{r}$ in the top surface, $\mathrm{S}_{2}$ in Figure 10, Eq. (9) may be re-arranged as 


$$
\left(u_{r}\right)_{\mathrm{n}}=\frac{\left(\rho u_{z} A\right)_{\mathrm{W}}-\left(\rho u_{z} A\right)_{\mathrm{e}}+\left(\rho u_{r} A\right)_{\mathrm{S}}+\left(\rho u_{\theta} A\right)_{\mathrm{t}}-\left(\rho u_{\theta} A\right)_{\mathrm{b}}}{(\rho A)_{\mathrm{n}}}
$$

where $\left(u_{r}\right)_{\mathrm{S}}$ has been obtained as $\left(u_{r}\right)_{\mathrm{n}}$ from the control volume which has a smaller radius $\left(\mathrm{S}_{1}\right.$ in Figure 10). Similarly, moving from $S_{3}$ to $S_{n-1}$ in Figure 10, all radial velocities $\left(u_{r}\right)$ are obtained as a function of $T, u_{\theta}$ and $u_{z}$. Therefore, all radial velocities and discretized forms of the equation of continuity, Eq. (9), are removed from the unknowns and nonlinear equations, respectively (except the discretized equations due to the control volumes which their north faces lie in $r=R, S_{n}$ in Figure 10).

The discretized form of equation of motion in the axial direction, Eq. (13), for the control volumes which their west faces lie in $\mathrm{z}=0$ may be rearranged as

$$
p_{\text {node }}=p_{\text {boundary }}-\frac{0.5 \times d z}{V}\left(\begin{array}{l}
\left(\rho u_{z} u_{z} A\right)_{\mathrm{e}}-\left(\rho u_{z} u_{z} A\right)_{\mathrm{W}}+\left(\rho u_{z} u_{r} A\right)_{\mathrm{n}}-\left(\rho u_{z} u_{r} A\right)_{\mathrm{s}} \\
+\left(\rho u_{\theta} u_{z} A\right)_{\mathrm{t}}-\left(\rho u_{\theta} u_{z} A\right)_{\mathrm{b}} \\
+\left(\left(\tau_{z z} A\right)_{\mathrm{e}}-\left(\tau_{z z} A\right)_{\mathrm{W}}+\left(\tau_{r z} A\right)_{\mathrm{n}}-\left(\tau_{r z} A\right)_{\mathrm{s}}+\left(\tau_{\theta z} A\right)_{\mathrm{t}}-\left(\tau_{\theta z} A\right)_{\mathrm{b}}\right.
\end{array}\right), \text {, }
$$

where $p_{\text {boundary }}$, which plays the same role as $p_{\mathrm{W}}$, as the boundary condition is given. Coefficient 0.5 in Eq. (23) stands for the distance of the boundary at $\mathrm{z}=0$ to the first node in the axial direction which is equal to $0.5 \times d z$. Here, $p_{\text {node }}$ is obtained as a function of $T, u_{\theta}$ and $u_{z}$ (since $u_{r}$ has been obtained as a function of $T, u_{\theta}$ and $u_{z}$ ) and it can be used as $p_{\mathrm{W}}$ in computation due to the next control volume on the right hand side, e.g. node $E$ in Figure 8, and so on:

$$
p_{\text {node }}=p_{\mathrm{W}}-\frac{d z}{V}\left(\begin{array}{l}
\left(\rho u_{z} u_{z} A\right)_{\mathrm{e}}-\left(\rho u_{z} u_{z} A\right)_{\mathrm{w}}+\left(\rho u_{z} u_{r} A\right)_{\mathrm{n}}-\left(\rho u_{z} u_{r} A\right)_{\mathrm{s}} \\
+\left(\rho u_{\theta} u_{z} A\right)_{\mathrm{t}}-\left(\rho u_{\theta} u_{z} A\right)_{\mathrm{b}} \\
+\left(\left(\tau_{z z} A\right)_{\mathrm{e}}-\left(\tau_{z z} A\right)_{\mathrm{w}}+\left(\tau_{r z} A\right)_{\mathrm{n}}-\left(\tau_{r z} A\right)_{\mathrm{s}}+\left(\tau_{\theta z} A\right)_{\mathrm{t}}-\left(\tau_{\theta z} A\right)_{\mathrm{b}}\right.
\end{array}\right)
$$

All the pressures $(p)$ can be obtained by this method as a function of $T, u_{\theta}$ and $u_{z}$.

Therefore, all the pressures and discretized forms of the equation of motion in the axial direction, Eq. (13), are removed from the unknowns and nonlinear equations, respectively.

It can be seen in Eqs. (23) and (24) that there is no need to give the shear stress equation, i.e. to determine the flow behavior, hence, the proposed approach is independent of Newtonian or nonNewtonian behavior of fluids.

The new corresponding nonlinear systems are now summarized as follows:

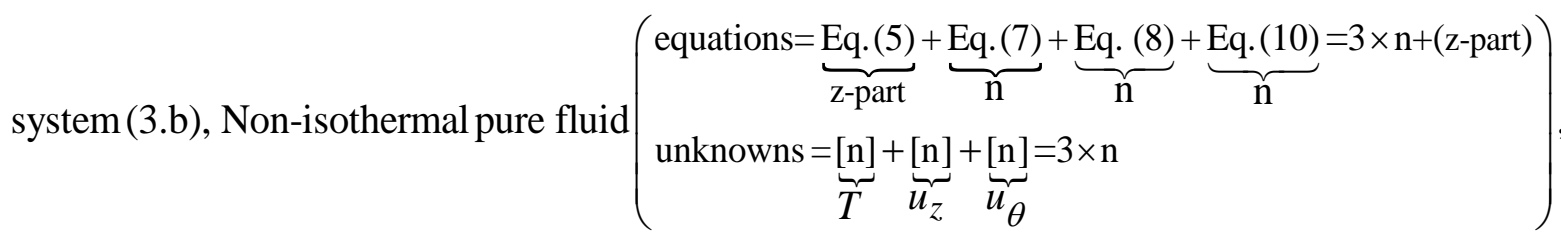

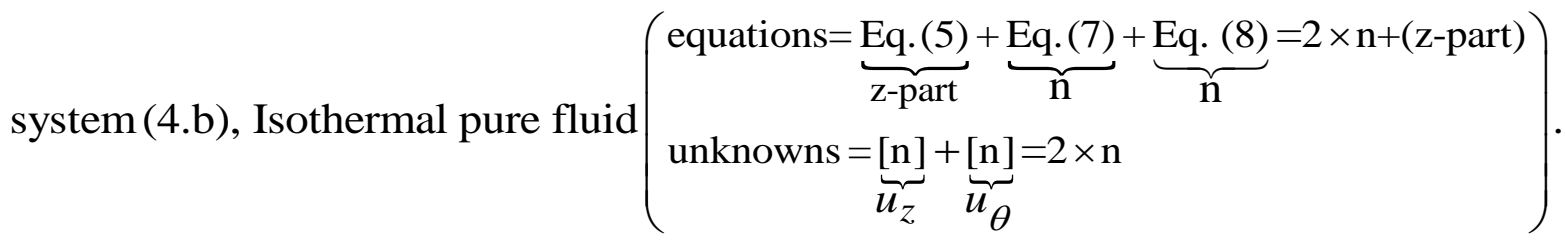

It can be seen that system (3.b) in comparison with its corresponding system, i.e. system (3.a), gives a reduction of $40 \%$ in the total number of the unknowns and equations. The reduction in this number for system (4.b) is $50 \%$ compared to its corresponding system (4.a). 
To show the importance of these reductions in the size of two nonlinear systems, it is assumed that, as an example, the tube is divided into 10,000 control volumes. Figure 11 compares the number of equations evaluated at each iteration of LMM for estimation of the Jacobian matrix (also the number of equations evaluated at each iteration of SDM) in which systems $(3, b)$ and $(4, b)$ reduce computations by 64 and $75 \%$, respectively, relative to their corresponding systems $(3, a)$ and $(4, a)$. Indeed, we can save considerable computer time in the calculation of the Jacobian matrix in LMM (or in the calculation of $\nabla f$ at each iteration of SDM) by using new nonlinear systems. Figure 12 shows the amount of allocated memory due to the Jacobian matrix (or the matrix $\mathrm{J}^{\mathrm{T}} \mathbf{J}$ ) in which the reductions obtained are same as those obtained in Figure 11, therefore, the storage requirements is considerably reduced by the proposed approach.

It should be noted that reduction rates due to Figure 11 and Figure 12 are independent of the number of the control volumes in the domain (based on the discussion presented in section 4) as follows:

Number of control volumes $=\mathrm{n}$

Number of equations for each control volume due to main system $=\mathrm{m} 1$

Number of equations for each control volume due to reduced system $=\mathrm{m} 2$

Reduction rate due to number of equations evaluated at each iteration of LMM for estimation of the Jacobian matrix (the number of equations evaluated at each iteration of SDM) = $1-\frac{(\mathrm{n} \times \mathrm{m} 2)^{2}}{(\mathrm{n} \times \mathrm{m} 1)^{2}}=1-\left(\frac{\mathrm{m} 2}{\mathrm{~m} 1}\right)^{2}$.

Reduction rate due to the amount of allocated memory for the Jacobian matrix (or the matrix $\mathbf{J}^{\mathrm{T}} \mathbf{J}$ ) $=$ $1-\frac{(\mathrm{n} \times \mathrm{m} 2)^{2}}{(\mathrm{n} \times \mathrm{m} 1)^{2}}=1-\left(\frac{\mathrm{m} 2}{\mathrm{~m} 1}\right)^{2}$.

Figure 13 comprises the number of additions (or multiplications) in the calculation of $\mathrm{J}^{\mathrm{T}} \mathrm{J}$ matrix at each iteration of LMM in which systems $(3, b)$ and $(4, b)$ reduce computations by 78 and $87 \%$, respectively, relative to their corresponding systems $(3, a)$ and $(4, a)$, therefore it is clear that the computer time for this computation is also significantly reduced by the proposed approach. Also, reduction rates due to Figure 13 are dependent on the number of the control volumes in the domain as follows:

Reduction rate due to the number of additions (or multiplications) in the calculation of $\mathrm{J}^{\mathrm{T}} \mathrm{J}$ matrix at each iteration of $\mathrm{LMM}=1-\frac{\left((\mathrm{n} \times \mathrm{m} 2)^{2} \times((\mathrm{n} \times \mathrm{m} 2)+1)\right) / 2}{\left((\mathrm{n} \times \mathrm{m} 1)^{2} \times((\mathrm{n} \times \mathrm{m} 1)+1)\right) / 2}=1-\left(\frac{\mathrm{m} 2}{\mathrm{~m} 1}\right)^{2}\left(\frac{\mathrm{m} 2+\frac{1}{\mathrm{n}}}{\mathrm{m} 1+\frac{1}{\mathrm{n}}}\right)$
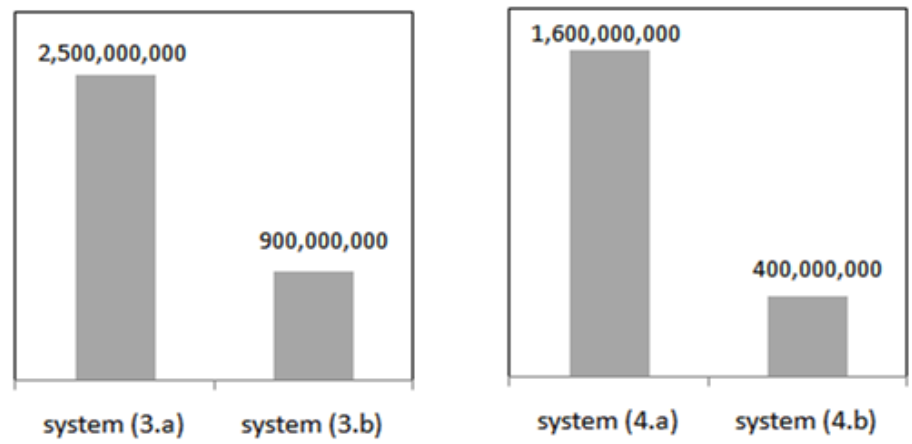

Figure11. Comparison of the number of equations evaluated in the estimation of Jacobian matrix in LMM (or the number of equations evaluated at each iteration of SDM), the number of control volumes in the domain $($ tube $)=10,000$. 

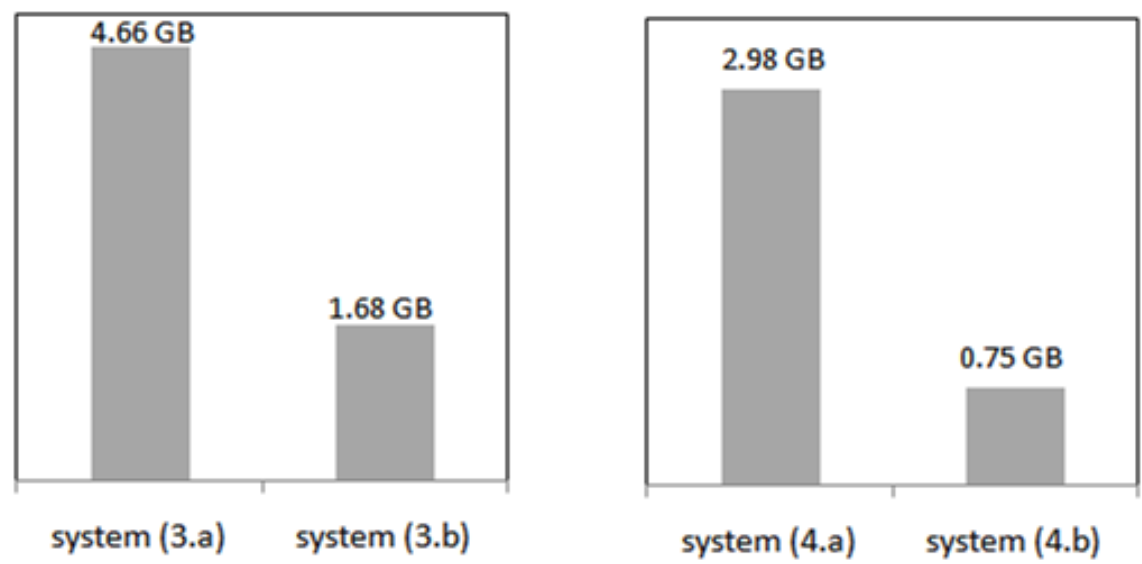

Figure12. Comparison of the amount of allocated memory for the Jacobian matrix (or the matrix $\mathbf{J}^{\mathrm{T}} \mathbf{J}$ ) in $L M M$ (GigaBytes), the number of control volumes in the domain (tube) $=10,000$.
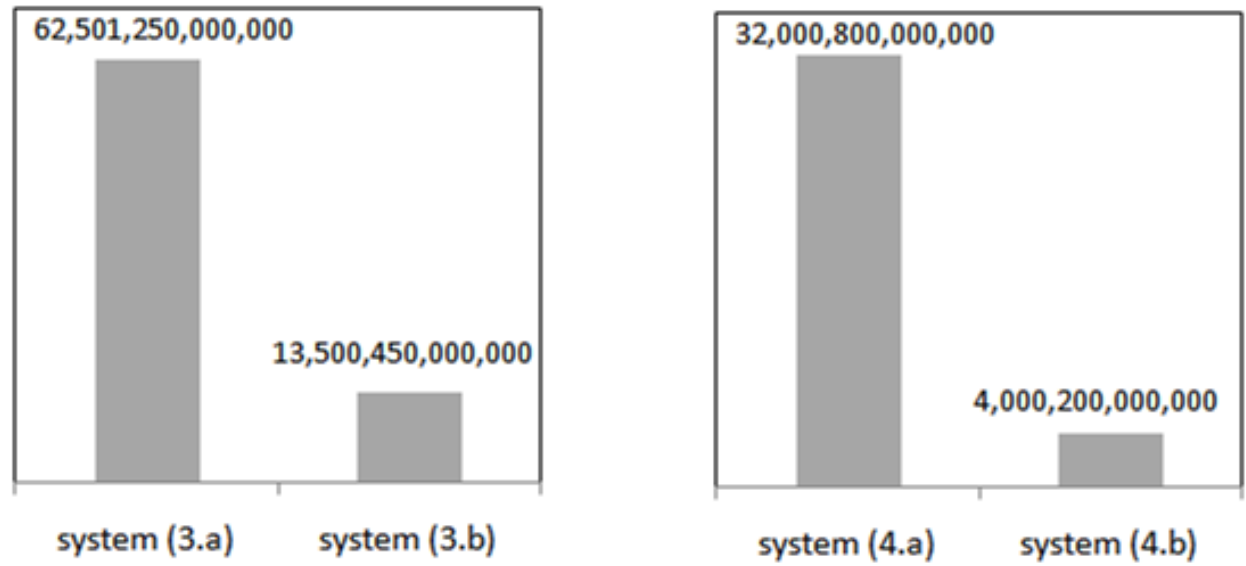

Figure13. Comparison of the number of additions (or multiplications) for calculation of $\mathbf{J}^{\mathrm{T}} \mathbf{J}$ matrix at each iteration of LMM, the number of control volumes in the domain (tube) =10,000.

\subsection{The Nanofluid (Binary Fluid)}

The discretized form of Eq. (6), Eq. (10), is written as

$\left(\phi \rho_{p} u_{z} A\right)_{\mathrm{e}}-\left(\phi \rho_{p} u_{z} A\right)_{\mathrm{W}}+\left(\phi \rho_{p} u_{r} A\right)_{\mathrm{n}}-\left(\phi \rho_{p} u_{r} A\right)_{\mathrm{S}}+\left(\phi \rho_{p} u_{\theta} A\right)_{\mathrm{t}}-\left(\phi \rho_{p} u_{\theta} A\right)_{\mathrm{b}}+$ other terms $=0$.

Here, Eqs. (9), (25), (11), (12), (13) and (14) are handled to construct more efficient nonlinear system. The control volumes which their south faces lie in $r=0$, the gray region in Figure 9 or $S_{1}$ in Figure 10 , are considered. Since $(A)_{\mathrm{S}}=0$, Eqs. (9) and (25) can be simplified as

$$
\begin{aligned}
& \left(\rho_{n f} u_{z} A\right)_{\mathrm{e}}-\left(\rho_{n f} u_{z} A\right)_{\mathrm{W}}+\left(\rho_{n f} u_{r} A\right)_{\mathrm{n}}+\left(\rho_{n f} u_{\theta} A\right)_{\mathrm{t}}-\left(\rho_{n f} u_{\theta} A\right)_{\mathrm{b}}=0, \\
& \left(\phi \rho_{p} u_{z} A\right)_{\mathrm{e}}-\left(\phi \rho_{p} u_{z} A\right)_{\mathrm{W}}+\left(\phi \rho_{p} u_{r} A\right)_{\mathrm{n}}+\left(\phi \rho_{p} u_{\theta} A\right)_{\mathrm{t}}-\left(\phi \rho_{p} u_{\theta} A\right)_{\mathrm{b}}+\text { other terms }=0 .
\end{aligned}
$$

If $\left(u_{r}\right)_{\mathrm{n}}$ is removed between Eqs. (26.a) and (26.b), the following equation can be derived:

$$
\begin{aligned}
& -\left(\frac{1}{\left(\phi \rho_{p} A\right)_{\mathrm{n}}}\right)\left(\left(\phi \rho_{p} u_{z} A\right)_{\mathrm{e}}-\left(\phi \rho_{p} u_{z} A\right)_{\mathrm{W}}+\left(\phi \rho_{p} u_{\theta} A\right)_{\mathrm{t}}-\left(\phi \rho_{p} u_{\theta} A\right)_{\mathrm{b}}+\text { other terms }\right)+ \\
& \left(\frac{1}{\left(\rho_{n f} A\right)_{\mathrm{n}}}\right)\left(\left(\rho_{n f} u_{z} A\right)_{\mathrm{e}}-\left(\rho_{n f} u_{z} A\right)_{\mathrm{W}}+\left(\rho_{n f} u_{\theta} A\right)_{\mathrm{t}}-\left(\rho_{n f} u_{\theta} A\right)_{\mathrm{b}}\right)=0
\end{aligned}
$$


Using Eq. (27) for the control volume which its west face lies in $\mathrm{z}=0$ and its south face lies in $\mathrm{r}=0$, $\left(u_{z}\right)_{\mathrm{e}}$ can be obtained as a function of $\phi, u_{\theta}$ and $T$ :

$\left(u_{z}\right)_{\mathrm{e}}=\left(\frac{1}{\left(\frac{\left(\rho_{n f} A\right)_{\mathrm{e}}}{\left(\rho_{n f} A\right)_{\mathrm{n}}}\right)-\left(\frac{\left.\left(\phi \rho_{p} A\right)_{\mathrm{e}}\right)}{\left(\phi \rho_{p} A\right)_{\mathrm{n}}}\right)}\right)\left(-\left(\frac{-\left(\phi \rho_{p} u_{z} A\right)_{\text {boundary }}+\left(\phi \rho_{p} u_{\theta} A\right)_{\mathrm{t}}-\left(\phi \rho_{p} u_{\theta} A\right)_{\mathrm{b}}+\text { other terms }}{\left(\phi \rho_{p} A\right)_{\mathrm{n}}}\right)\right)$,

where the subscript "boundary" denotes the boundary conditions at the tube inlet. This $\left(u_{z}\right)_{\mathrm{e}}$ can be used as $\left(u_{z}\right)_{\mathrm{W}}$ in Eq. (27) to obtain $\left(u_{z}\right)_{\mathrm{e}}$ for the control volume on the right hand side, e.g. node $\mathrm{E}$ in Figure 8, and so on, hence, all the axial velocities are obtained in this region, $S_{1}$ in Figure 10, as a function of $\phi, u_{\theta}$ and $T$, also, using either Eq. (26.a) or Eq. (26.b), $\left(u_{r}\right)_{\mathrm{n}}$ can then be obtained as a function of $\phi, u_{\theta}$ and $T$ in this region. Therefore, for the control volumes which their south faces lie in $\mathrm{r}=0$, all $u_{z}$ and $u_{r}$ are obtained as a function of $\phi, u_{\theta}$ and $T$. This approach can be used for top control volumes, $S_{2}$ in Figure 10, therefore $\left(u_{r}\right)_{\mathrm{n}}$ is removed between Eqs. (9) and (25) as

$$
\begin{aligned}
& -\left(\frac{1}{\left(\phi \rho_{p} A\right)_{\mathrm{n}}}\right)\left(\left(\phi \rho_{p} u_{z} A\right)_{\mathrm{e}}-\left(\phi \rho_{p} u_{z} A\right)_{\mathrm{W}}-\left(\phi \rho_{p} u_{r} A\right)_{\mathrm{s}}+\left(\phi \rho_{p} u_{\theta} A\right)_{\mathrm{t}}-\left(\phi \rho_{p} u_{\theta} A\right)_{\mathrm{b}}+\text { other terms }\right)+ \\
& \left(\frac{1}{\left(\rho_{n f} A\right)_{\mathrm{n}}}\right)\left(\left(\rho_{n f} u_{z} A\right)_{\mathrm{e}}-\left(\rho_{n f} u_{z} A\right)_{\mathrm{W}}-\left(\rho_{n f} u_{r} A\right)_{\mathrm{s}}+\left(\rho_{n f} u_{\theta} A\right)_{\mathrm{t}}-\left(\rho_{n f} u_{\theta} A\right)_{\mathrm{b}}\right)=0
\end{aligned}
$$

Similarly, for the control volume which its west face lies in $\mathrm{z}=0,\left(u_{z}\right)_{\mathrm{e}}$ can be obtained from Eq. (29) as a function of $\phi, u_{\theta}$ and $T$ :

$$
\left(u_{z}\right)_{\mathrm{e}}=\left(\frac{1}{\left(\frac{\left.\rho_{n f} A\right)_{\mathrm{e}}}{\left.\left(\rho_{n f} A\right)_{\mathrm{n}}\right)}-\left(\frac{\left.\left(\phi \rho_{p} A\right)_{\mathrm{e}}\right)}{\left(\phi \rho_{p} A\right)_{\mathrm{n}}}\right)\right.}\right)\left(-\left(\frac{-\left(\phi \rho_{p} u_{z} A\right)_{\text {boundary }}-\left(\phi \rho_{p} u_{r} A\right)_{\mathrm{s}}+\left(\phi \rho_{p} u_{\theta} A\right)_{\mathrm{t}}-\left(\phi \rho_{p} u_{\theta} A\right)_{\mathrm{b}}+\text { other terms }}{\left(\phi \rho_{p} A\right)_{\mathrm{n}}}\right)\right),
$$

where $\left(u_{r}\right)_{\mathrm{s}}$ has been obtained as $\left(u_{r}\right)_{\mathrm{n}}$ from the previous control volume with a smaller radius $\left(\mathrm{S}_{1}\right.$ in Figure 10). This $\left(u_{z}\right)_{\mathrm{e}}$ can be used as $\left(u_{z}\right)_{\mathrm{W}}$ in Eq. (29) for the next control volume on the right hand side, e.g. node $\mathrm{E}$ in Figure 8, to obtain $u_{z}$ in this region, $\mathrm{S}_{2}$ in Figure 10. Also, using either Eq. (9) or Eq. (25), $\left(u_{r}\right)_{\mathrm{n}}$ can be obtained as a function of $\phi, u_{\theta}$ and $T$. By repeating this method from $\mathrm{S}_{3}$ to $\mathrm{S}_{\mathrm{n}-1}$, all $\left(u_{r}\right)$ and $\left(u_{z}\right)$ are obtained as a function of $\phi, u_{\theta}$ and $T$ in these regions. The control volumes which their north faces lie in $r=R\left(S_{n}\right.$ in Figure 10) are now considered, since $\left(u_{r}\right)_{\mathrm{n}}=0$, Eq. (9) is simplified as

$\left(\rho_{n f} u_{z} A\right)_{\mathrm{e}}-\left(\rho_{n f} u_{z} A\right)_{\mathrm{W}}-\left(\rho_{n f} u_{r} A\right)_{\mathrm{s}}+\left(\rho_{n f} u_{\theta} A\right)_{\mathrm{t}}-\left(\rho_{n f} u_{\theta} A\right)_{\mathrm{b}}=0$. 
For the control volume which its west face lies in $\mathrm{z}=0$ and its north face lies in $\mathrm{r}=\mathrm{R},\left(u_{z}\right)_{\mathrm{e}}$ can be obtained from Eq. (31):

$\left(u_{z}\right)_{\mathrm{e}}=\left(\frac{\left(\rho_{n f} u_{z} A\right)_{\text {boundary }}+\left(\rho_{n f} u_{r} A\right)_{\mathrm{s}}-\left(\rho_{n f} u_{\theta} A\right)_{\mathrm{t}}+\left(\rho_{n f} u_{\theta} A\right)_{\mathrm{b}}}{\left(\rho_{n f} A\right)_{\mathrm{e}}}\right)$,

where $\left(u_{r}\right)_{\mathrm{S}}$ has been obtained as $\left(u_{r}\right)_{\mathrm{n}}$ from the previous control volume with a smaller radius $\left(\mathrm{S}_{\mathrm{n}-1}\right.$ in Figure 10). This $\left(u_{z}\right)_{\mathrm{e}}$ can be used as $\left(u_{z}\right)_{\mathrm{W}}$ in Eq. (31) for the next control volume on the right hand side, e.g. node $\mathrm{E}$ in Figure 8, to obtain $u_{z}$ in this region. Therefore, all $\left(u_{r}\right)$ and $\left(u_{z}\right)$ are obtained as a function of $\phi, u_{\theta}$ and $T$ and they are removed from the unknowns. Also, all discretized equations of the nanofluid continuity, Eq. (9), and discretized equations of the nanoparticle continuity, Eq. (25), are removed from the nonlinear equations except the discretized equations of the nanoparticle continuity for the control volumes which their the north faces lie in $r=R\left(S_{n}\right.$ in Figure 10$)$. All pressures can also be obtained from Eq. (13) as a function of $\phi, u_{\theta}$ and $T$ similar to the pure fluid explained in section 5.1. Hence, all the pressures and discretized equations due to the equation of motion in the axial direction, Eq. (13), are removed from the unknowns and nonlinear equations, respectively.

The new nonlinear systems are now summarized as follows:

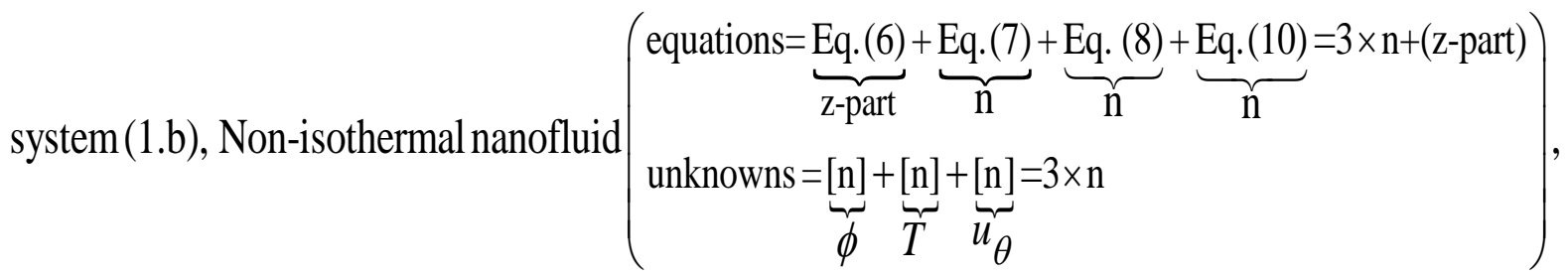

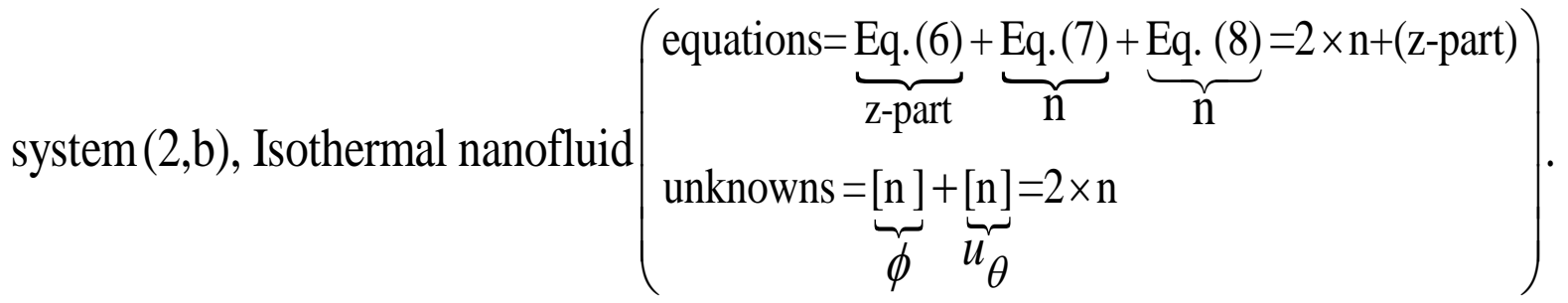

It can be seen that system (1.b) in comparison with its corresponding system, system (1.a), gives reduction of approximately $50 \%$ in the total number of the unknowns and equations. The reduction in this number for system (2.b) is approximately $60 \%$ compared to its corresponding systems (2.a).

Once again, as an example, it is assumed that the tube is divided into 10,000 control volumes. Figure 14, which is similar to Figure 11, compares the number of equations evaluated at each iteration of LMM for estimation of the Jacobian matrix (the number of equations evaluated at each iteration of SDM) in which systems (1.b) and (2,b) reduce computations by 75 and $84 \%$, respectively, relative to their corresponding systems (1.a) and (2,a). Figure 15, which is similar to Figure 12, compares the amount of allocated memory due to the Jacobian matrix (or the matrix $\mathrm{J}^{\mathrm{T}} \mathbf{J}$ ) in which the reductions obtained are same as those obtained in Figure 14. Figure 16, which is similar to Figure 13, comprises the number of additions (or multiplications) in the calculation of $\mathrm{J}^{\mathrm{T}} \mathbf{J}$ matrix at each iteration of LMM in which systems (1.b) and (2,b) reduce computations by 87 and $94 \%$, respectively, relative to their corresponding systems (1.a) and (2,a). 
An Efficient Computational Approach for Laminar Single Phase Flow of a Fluid (A Single Component or a Homogeneous Mixture)

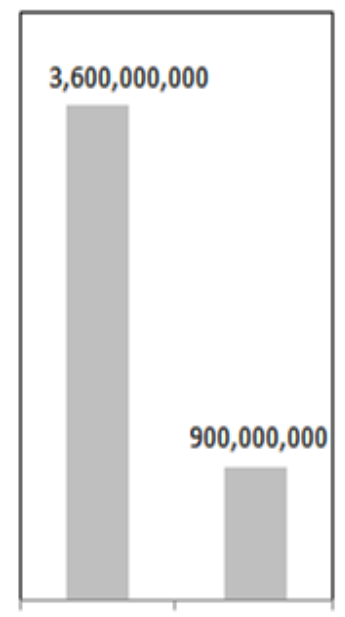

system (1.a) system (1.b)

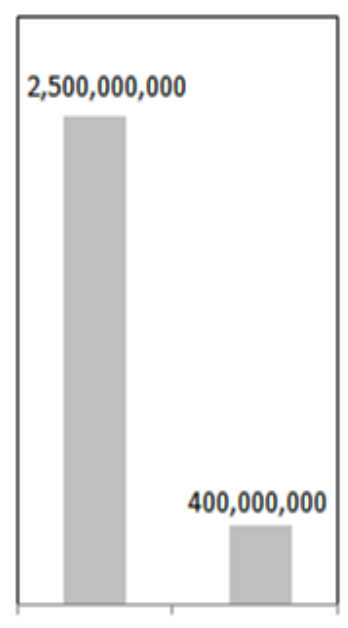

system (2.a) system (2.b)

Figure14. Comparison of the number of equations evaluated in the estimation of Jacobian matrix in LMM (or the number of equations evaluated at each iteration of SDM), the number of control volumes in the domain $($ tube $)=10,000$.
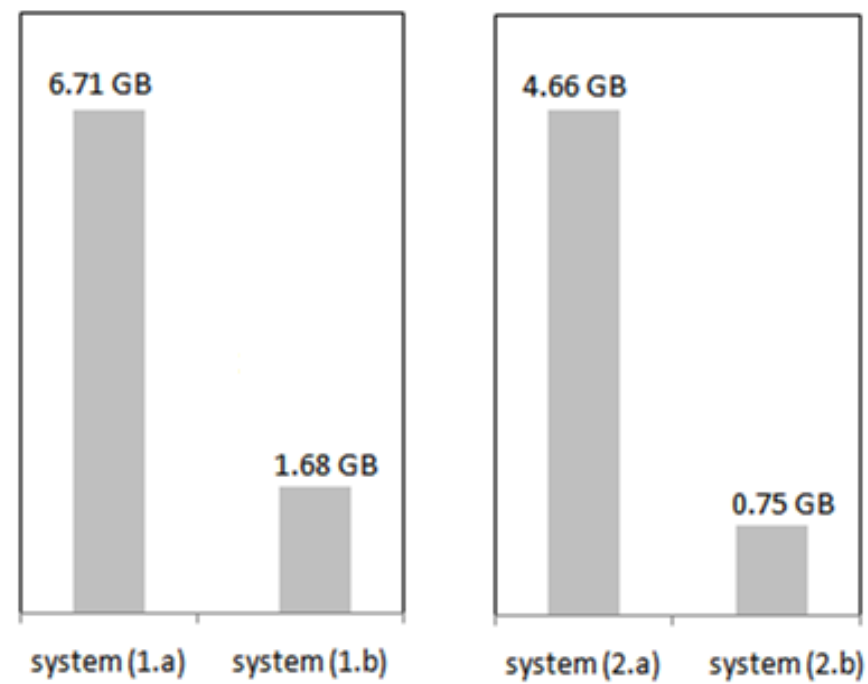

Figure15. Comparison of the amount of allocated memory for the Jacobian matrix (or the matrix $\mathbf{J}^{\mathrm{T}} \mathbf{J}$ ) in LMM (GigaBytes), the number of control volumes in the domain (tube) $=10,000$.
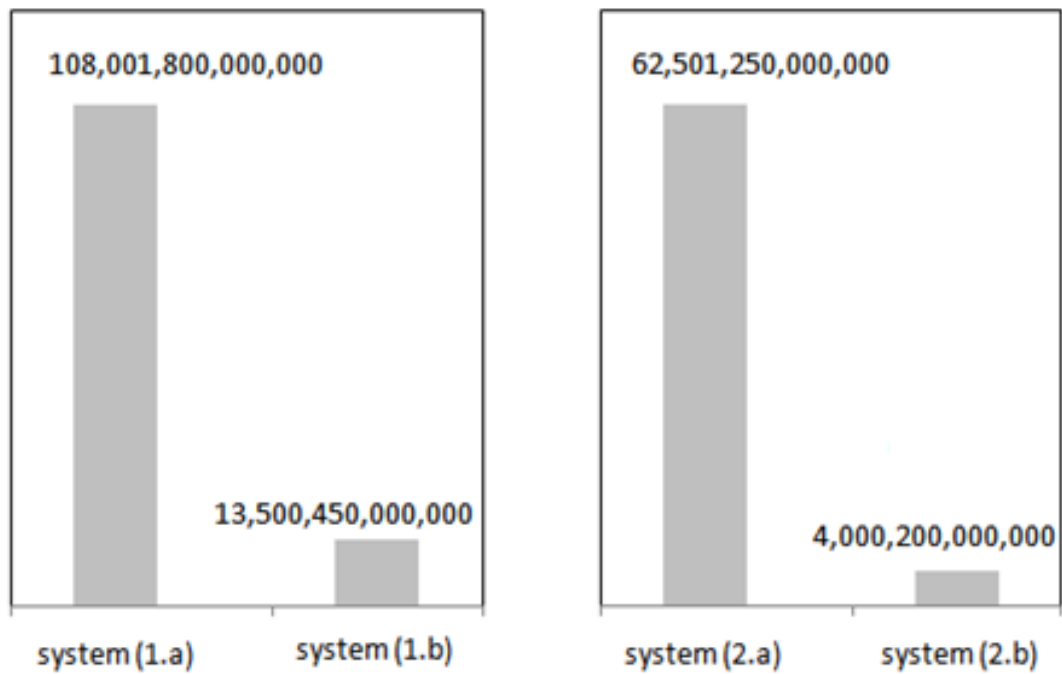

Figure16. Comparison of the number of additions (or multiplications) for calculation of $\mathbf{J}^{\mathrm{T}} \mathbf{J}$ matrix at each iteration of LMM, the number of control volumes in the domain (tube) $=10,000$. 


\section{CONCLUSiON}

In this paper, we have proposed an efficient computational approach for laminar single phase flow of a fluid (a single component or a homogeneous mixture) in which the size of the nonlinear system due to these problems is greatly reduced leading to a considerable improvement in computer implementation of numerical algorithms. In general, the proposed approach gives a reduction of $40 \%$ in the total number of the unknowns and equations for the pure fluid. The reduction in this number for the nanofluid (binary fluid) is $50 \%$. Also, it can be about $57 \%$ for the ternary fluid.

\section{REFERENCES}

[1] Tian, Z. F., Tu, J. Y., \& Yeoh, G. H. (2007). Numerical modelling and validation of gas-particle flow in an in-line tube bank. Computers \& chemical engineering, 31(9), 1064-1072.

[2] Xuan Xuan, Z. C., \& Zhang, X. K. (2008). Simulation of Stokes flow over microelectrodes with leastsquares meshfree method. Simulation Modelling Practice and Theory, 16(3), 294-314.

[3] He, Y., Men, Y., Zhao, Y., Lu, H., \& Ding, Y. (2009). Numerical investigation into the convective heat transfer of $\mathrm{TiO} 2$ nanofluids flowing through a straight tube under the laminar flow conditions. Applied Thermal Engineering, 29(10), 1965-1972.

[4] Bianco, V., Manca, O., \& Nardini, S. (2011). Numerical investigation on nanofluids turbulent convection heat transfer inside a circular tube. International Journal of Thermal Sciences, 50(3), 341-349.

[5] Nazir, A., \& Mahmood, T. (2011). Analysis of flow and heat transfer of viscous fluid between contracting rotating disks. Applied mathematical modelling, 35(7), 3154-3165.

[6] Lopes, R. J., \& Quinta-Ferreira, R. M. (2011). Numerical assessment of diffusion-convection-reaction model for the catalytic abatement of phenolic wastewaters in packed-bed reactors under trickling flow conditions. Computers \& chemical engineering, 35(12), 2706-2715.

[7] Qian, L., Feng, X., \& He, Y. (2012). The characteristic finite difference streamline diffusion method for convection-dominated diffusion problems. Applied Mathematical Modelling, 36(2), 561-572.

[8] Mittal, R. C., \& Jain, R. K. (2012). Redefined cubic B-splines collocation method for solving convectiondiffusion equations. Applied Mathematical Modelling, 36(11), 5555-5573.

[9] Karimi, M., Akdogan, G., Dellimore, K. H., \& Bradshaw, S. M. (2012). Quantification of numerical uncertainty in computational fluid dynamics modelling of hydrocyclones. Computers \& chemical engineering, 43, 45-54.

[10] Doheim, M. A., Gawad, A. A., Mahran, G. M. A., Abu-Ali, M. H., \& Rizk, A. M. (2013). Numerical simulation of particulate-flow in spiral separators: Part I. Low solids concentration ( $0.3 \%$ \& $3 \%$ solids). Applied Mathematical Modelling, 37(1-2), 198-215.

[11] Corcione, M., Habib, E., \& Quintino, A. (2013). A two-phase numerical study of buoyancy-driven convection of alumina-water nanofluids in differentially-heated horizontal annuli. International Journal of Heat and Mass Transfer, 65, 327-338.

[12] Salinas-Vázquez, M., Vicente, W., Barrios, E., Martínez, E., Palacio, A., \& Rodríguez, A. (2013). A lowMach number method for the numerical simulation of complex flows. Applied Mathematical Modelling, $37(22), 9132-9146$.

[13] Ellahi, R. (2013). The effects of MHD and temperature dependent viscosity on the flow of non-Newtonian nanofluid in a pipe: analytical solutions. Applied Mathematical Modelling, 37(3), 1451-1467.

[14] Wang, W., Guo, J., Zhang, S., Yang, J., Ding, X., \& Zhan, X. (2014). Numerical study on hydrodynamic characteristics of plate-fin heat exchanger using porous media approach. Computers \& chemical engineering, 61, 30-37.

[15] Lakshminarayan, V., Farhat, C., \& Main, A. (2014). An embedded boundary framework for compressible turbulent flow and fluid-structure computations on structured and unstructured grids. International Journal for Numerical Methods in Fluids, 76(6), 366-395.

[16] Platzek, F. W., Stelling, G. S., Jankowski, J. A., Patzwahl, R., \& Pietrzak, J. D. (2016). An efficient semi-implicit subgrid method for free-surface flows on hierarchical grids. International Journal for Numerical Methods in Fluids, 80(12), 715-741.

[17] Ferziger, J. H., Perić, M., \& Street, R. L. (2002). Computational methods for fluid dynamics (Vol. 3, pp. 196-200). Berlin: springer.

[18] Versteeg, H. K., \& Malalasekera, W. (1995). An introduction to computational fluid dynamics. Finite Volume Method, Essex, Longman Scientific \& Technical.

[19] Nocedal, J., \& Wright, S. (1999). Numerical optimization. Springer Science \& Business Media. 
An Efficient Computational Approach for Laminar Single Phase Flow of a Fluid (A Single Component or a Homogeneous Mixture)

[20] Peker, S. M., \& Helvaci, S. S. (2011). Solid-liquid two phase flow. Elsevier.

[21] Bird, R. B., Stewart, W. E., \& Lightfoot, E. N. (2007). Transport phenomena. Wiley.

[22] Azimi, S. S., \& Kalbasi, M. (2014). Numerical study of dynamic thermal conductivity of nanofluid in the forced convective heat transfer. Applied Mathematical Modelling, 38(4), 1373-1384.

Citation: Seyyed Shahabeddin Azimi, Mansour Kalbasi. (2019)" An Efficient Computational Approach for Laminar Single Phase Flow of a Fluid (A Single Component or a Homogeneous Mixture)", International Journal of Modern Studies in Mechanical Engineering, 5(4), pp. 5-22 DOI: http://dx.doi. org/10.20431/2454-9711.0504002

Copyright: (C) 2019 Authors, This is an open-access article distributed under the terms of the Creative Commons Attribution License, which permits unrestricted use, distribution, and reproduction in any medium, provided the original author and source are credited. 